\title{
RADICAL ADDITION POLYMERISATION OF ACRYLATES IN A BUSS-KNEADER
}

\author{
E.J. TROELSTRA, L.L. V. DIERENDONCK AND L.P.B.M. JANSSEN
}

Department of Chemical Engineering, Groningen University. Nijenborgh 4.9747 AG Groningen, The Netherlands

\author{
S. MAEDER AND A. RENKEN*
}

Institut de Génie Chimique, Ecole Polytechnique Fédérale de Lausanne, CH-1015 Lausanne, Switzerland

\begin{abstract}
The radical addition co-polymerisation of 2-hydroxyethylmethacrylate and butylacrylate is carried out in a continuously operating Buss-Kneader. To calculate temperature profiles over the length of the kneader the heat balance is solved. For the heat transfer coefficient a model based on the penetration theory is used. This model is experimentally verified. The reaction kinetics of the radical addition polymerisation are studied in a differential scanning calorimeter. The polymerisation kinetics are modeled using non-stationary radical concentrations. The calculated temperature profiles over the length of the Buss-Kneader are a good approximation of the experimental data.
\end{abstract}

\section{INTRODUCTION}

The powder coating technology is one possible way to avoid the use of solvents in the coating industry. For the production of the base polymer of these powder coatings, however, solvents are commonly used to keep the viscosity low. Reactive extrusion offers a possibility to carry out the polymerisation reaction without using a solvent. In literature several polymerisation reactions have been studied on co-rotating and counter rotating twinscrew extruders (Ganzeveld, 1993; Jongbloed, 1995). For the Buss-Kneader, only the ionic polymerisation of polyacetals (Aeppli, 1989) and the condensation polymerisation of silicones (Franz,1988) are described in literature. In this paper the co-polymerisation of $n$-butylacrylate (BA) and 2-hydroxyethylmethacrylate (HEMA) is studied in a Buss-Kneader. To solve the heat balance of the continuously operating Buss-Kneader as a polymerisation reactor, the polymerisation kinetics were studied by means of Differential Scanning Calorimetry (DSC) and the heat transfer of the Buss-Kneader was studied with model liquids.

\section{WORKING MECHANISM OF THE BUSS-KNEADER}

The Buss-Kneader differs from all other screw type machines. The screw of this single screw design is not only rotating but simultaneously reciprocating in axial direction during every rotation. The continuously operating kneader used in this work is a Buss-Kneader PR 46. This model has a screw diameter of $46 \mathrm{~mm}$. The ratio L/D equals 15. The screw flights are interrupted and, from the barrel, kneading pins are inserted into the barrel. Relative to the screw the kneading pins make an oscillating movement through the screw flights (figure 1). The interaction between screw flights and kneading pins results in shear stress, a reorientation of the material (Elemans, 1989) and a good self-cleaning efficiency.

\footnotetext{
To whom correspondence should be addressed
} 

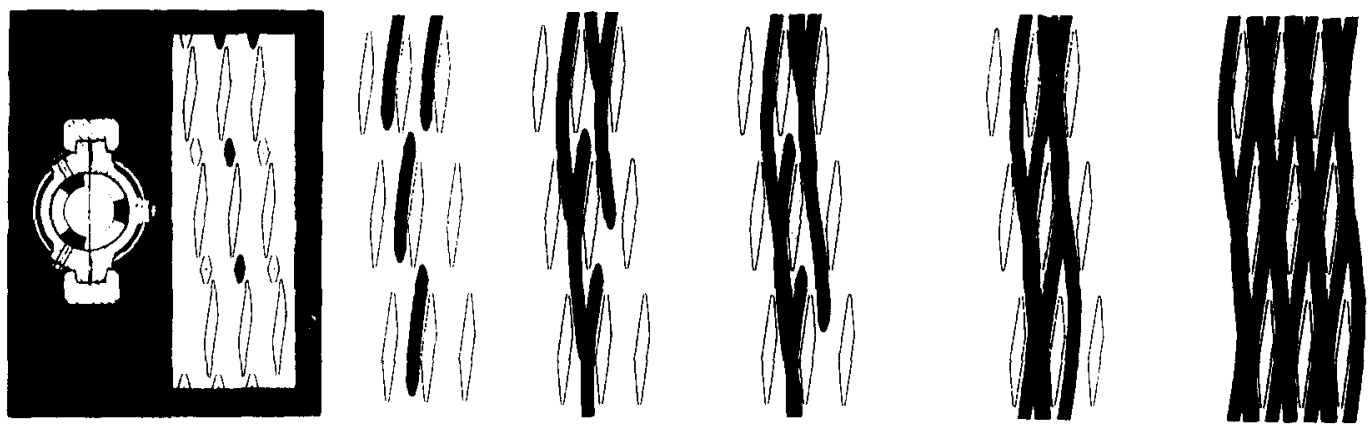

Figure $1 \quad$ Oscillating movement of the kneading pins through the screw flights (Franz, 1984).

\section{CHARACTERISATION OF THE BUSS-KNEADER}

To be able to solve the heat balance of the polymerisation in the kneader, a reactor model for the kneader is necessary. The cumulative residence time distribution $(\mathrm{F}(\mathrm{t}))$ measured by Elemans(1989) could be well fitted with a cascade of 10 ideal continuous stirred tank reactors (CSTR). These measurements were carried out on a BussKneader PR46 with a length corresponding to 11 diameters (11 D) with molten polymers as model fluids.

\section{Residence time}

In the present study, breakthrough times $\left(t_{b t}\right)$ were measured by injecting carbon black, suspended in $5 \mathrm{ml}$ of the $\mathrm{BA} / \mathrm{HEMA}$ monomer mixture, at the inlet of the kneader under polymerisation conditions.

By neglecting the density change of the polymerisation mixture, the measured mean residence time $(\bar{t})$ corresponds to the space time $(\tau)$.

$$
\tau=\frac{f \cdot V}{Q_{v, 0}} \cong \bar{t}
$$

Where $f$ is the degree of fill of the kneader.

The breakthrough times $\left(t_{b t}\right)$ were measured as a function of the monomer feed and the srew speed (N). In principle the breakthrough time is related to the mean residence time by eq. 2 :

$$
\mathrm{t}_{\mathrm{bt}}=\mathrm{C} \cdot \overrightarrow{\mathrm{t}} \cong C \cdot f \cdot \frac{V}{Q_{v}}
$$

From experiments (Elemans, 1989) it can be concluded that for a kneader $\mathrm{C}$ is independent of the throughput. These experiments show that $\mathrm{C} \approx 0.5$ at a screw speed of $200 \mathrm{rpm}$.

In Fig. 2 the measured breakthrough time as function of the volumetric flow rate at constant screw speed are compared with the calculated space time assuming that the value of $C \cdot f$ is constant with $C \cdot f=0.13$. 


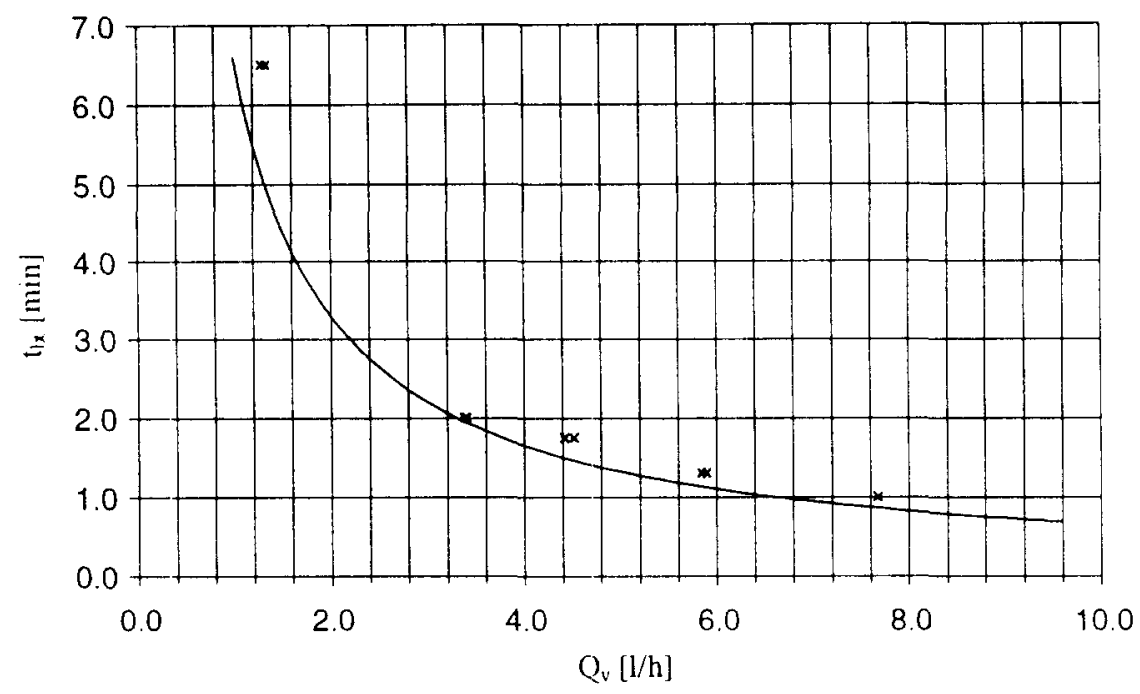

Figure $2 \quad$ Measured (+) and calculated (-) breakthrough times as a function of flowrate. $N=285 \mathrm{rpm}$

Because $C$ is a constant, the degree of fill ( $f$ ) is also constant at different throughput and a screw speed of $285 \mathrm{rpm}$.

\section{Heat transfer}

The Buss-Kneader has an oil heated screw and barrel. The heat transfer coefficient between the reaction mixture and the wall of the screw and the wall of the barrel can be assumed to be equal $\left(U_{b}=U_{s}=U\right)$. Based on the penetration theory, Jepson (1953) proposed a model to calculate the mean heat transfer coefficient:

$$
h=\frac{\lambda}{\delta} \operatorname{erf}\left[\frac{\delta}{2 \sqrt{\frac{a}{N}}}\right]
$$

Where $\delta$ is the flight clearance, $N$ is the screw speed and a the thermal diffusivity $\left(a=\lambda \rho c_{p}\right)$.

$\mathrm{U}$ was determined experimentally using different silicone oils and glycerol. The temperature of the silicone oil was measured at two points over the length of the kneader at a distance of $54 \mathrm{~mm}$ from each other $\left(T_{1}\right.$ and $\left.T_{2}\right)$. Due to the high throughput of the heating oil, the wall temperature is assumed to be constant and measured in the heaters $\left(T_{\text {oil }}\right)$. The overall heat transfer can now be calculated with:

$$
U=\frac{Q_{m} c_{p}}{A} \ln \left[\frac{T_{o i l}-T_{1}}{T_{o l}-T_{2}}\right]
$$

The area $A$ is the heat exchange area, including the area of the kneading pins and the area of the screw flights. Fig. 3 shows a parity plot of the calculated mean transfer coefficient (Eq.3) and the experimental overall heat transfer coefficient. The measured over-all heat transfer coefficient are slightly higher for experiments with silicon oil and lower for glycerol. As the later are in general rather high, heat transfer resistance on the oil side may influence the over-all heat transfer. Nevertheless equation (3) seems to give a good estimation of the heat transfer coefficient. 


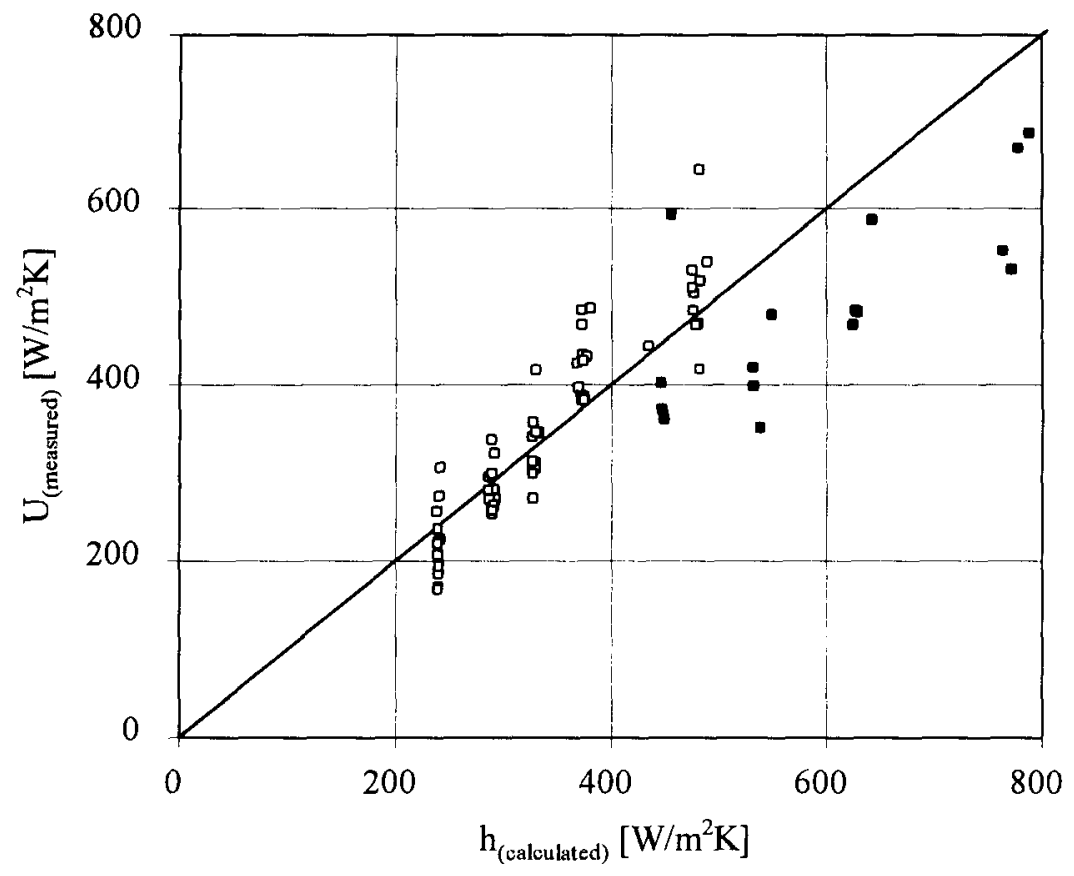

Figure 3 Parity plot of the theoretical and the experimental heat transfer coefficient. $\square$ Values measured with silicone oils with a kinematic viscosity of $0.5 \cdot 10^{-3}, 1.0 \cdot 10^{-3}$ and $5.0 \cdot 10^{-3} \mathrm{~m}^{2} \mathrm{~s}^{-1}$ at $25^{\circ} \mathrm{C}$; values measured with glycerine with a kinematic viscosity of $0.75 \cdot 10^{-3} \mathrm{~m}^{2} \mathrm{~s}^{-1}$ at $25^{\circ} \mathrm{C}$.

\section{POLYMERISATION KINETICS}

The copolymerisation kinetics were studied using isothermal and non-isothermal differential scanning calorimetry (DSC). The aluminium crucibles have a volume of $25 \mu \mathrm{l}$. They are closed with a cover of stainless steel and a Kalret $^{\mathrm{TM}}$ joint is used to make the crucible air tight. All experiments are performed with about $10 \mu$ l of polymerisation mixture to ensure a good temperature control (Fleury, 1993). For non-isothermal studies, a linear temperature ramp was imposed.

DSC experiments allow to determine the instantaneous heat production of the copolymerisation as function of time. With the mass balance for a closed reaction system, the following relationship between the rate of monomer conversion and the measured heat flow $\left(q_{m}\right)$ can be established:

$$
\frac{d X}{d t}=\frac{-R_{M}}{c_{M, 0}}=\frac{1}{\Delta h} q_{m}
$$

The total enthalpy can be determined by integrating the heat flow over the time:

$$
\Delta h=\int_{0}^{\infty} q_{m} d t
$$

The monomer conversion as a function of time is given by:

$$
X(t)=\int_{0}^{t} \frac{d X}{d t} d t^{\prime}
$$

For the study of the copolymerisation it is assumed that the reaction enthalpy is independent of the monomer composition. This is in most cases not correct and therefore the calculated conversions from DSC-experiments were compared to results obtained by chromatographic analyses of the reaction mixture (Maeder and Renken, 
1995). For the system n-butylacrylate/2-hydroxyethylmethacrylate it could be shown that the DSC-measurements are in good agreement with the real degree of conversion.

The kinetic model used include, besides initiation, propagation and termination steps, the influence of the inhibitor (Y). No steady state assumption was made. The mass balances for the reacting species and the kinetic equations are summarised as follows:

Mass balances:

$\frac{d X_{M}}{d t}=\frac{1}{c_{M, 0}} \cdot\left(-R_{M}\right) \cdot \frac{\rho_{0}}{\rho}$

$\frac{d X_{I}}{d t}=\frac{1}{c_{I, 0}} \cdot\left(-R_{I}\right) \cdot \frac{\rho_{0}}{\rho}$

$\frac{d X_{Y}}{d t}=\frac{1}{c_{Y, 0}} \cdot\left(-R_{Y}\right) \cdot \frac{\rho_{0}}{\rho}$

$\frac{d \mathrm{Y}_{\Lambda 0}}{d t}=\frac{1}{C_{M, 0}} \cdot\left(-R_{\Lambda 0}\right) \cdot \frac{\rho_{0}}{\rho}$

where $\quad \mathrm{Y}_{\wedge, 0}=\frac{\Lambda_{0}}{c_{M 0}}$
Kinetics rates:

$$
\begin{aligned}
& R_{M}=-k_{p} \cdot c_{M} \cdot \Lambda_{0} \\
& R_{I}=-k_{d} \cdot c_{I} \\
& R_{Y}=-k_{y} \cdot c_{Y} \cdot \Lambda_{0} \\
& R_{\Lambda 0}=2 \cdot f \cdot k_{d} \cdot c_{I}-k_{t} \cdot \Lambda_{0}^{2}-k_{y} \cdot \Lambda_{0} \cdot c_{Y}
\end{aligned}
$$

with $\quad k_{i}=A_{i} \exp \left(\frac{-E_{i}}{R T}\right)$

The total concentration of radicals is given by the zero moment:

$$
\Lambda_{0}=\sum_{k=1}^{\infty} M_{k}^{*}
$$

where $\mathrm{M}_{\mathrm{k}}$ denotes a living copolymer (radical) of $\mathbf{k}$ monomer units. No distinction was made between the different terminal units. $\Lambda_{0}$ represents the total radical concentration. The Arrhenius law was used to describe the temperature dependence of the different rate constants $\left(\mathrm{k}_{\mathrm{i}}\right)$.

The concentrations can be calculated from the conversion of the different reactants $i$ :

$c_{i}=c_{i, 0} \cdot\left(1-X_{i}\right) \cdot \frac{\rho}{\rho_{0}}$

The propagation and inhibition constants as well as the corresponding activation energies were estimated by nonlinear fitting to experimental results by using the commercial available SimuSolv-program (Steiner et al., 1990). For the parameter estimation a constant reaction volume was assumed $\left(\rho \cong \rho_{0}\right)$.

\begin{tabular}{|l|l|l|l|}
\hline Kinetics constant & Pre-exponential factor & Activation Energy & Reference \\
\hline $\mathrm{k}_{\mathrm{d}}$ (initiator) & $1.6910^{14}\left[\mathrm{~s}^{-1}\right]$ & $125000\left[\mathrm{~J} \mathrm{~mol}{ }^{-1}\right]$ & Louie et al. (1985) \\
\hline $\mathrm{k}_{\mathrm{t}}$ (termination) & $98000\left[\mathrm{~m}^{3} \mathrm{~mol}^{-1} \mathrm{~s}^{-1}\right]$ & $3000\left[\mathrm{~J} \mathrm{~mol}{ }^{-1}\right]$ & Louie et al. (1985) \\
\hline $\mathrm{k}_{\mathrm{p}}$ (propagation) & $492\left[\mathrm{~m}^{3} \mathrm{~mol}^{-1} \mathrm{~s}^{-1}\right]$ & $13300\left[\mathrm{~J} \mathrm{~mol}{ }^{-1}\right]$ & this study \\
\hline $\mathrm{k}_{\mathrm{y}}$ (inhibition) & $500000\left[\mathrm{~m}^{3} \mathrm{~mol}^{-1} \mathrm{~s}^{-1}\right]$ & $30795\left[\mathrm{~J} \mathrm{~mol}{ }^{-1}\right]$ & this study \\
\hline
\end{tabular}

Table 1: Kinetic parameters

Since the purpose of the kinetics study is the modelling of the reactive extrusion, it is necessary to take into account the axial temperature profile in the reactor. The kinetics model was therefore compared with experimental results obtained under non-isothermal conditions. In Fig. 4, the predicted and measured polymerisation rate are compared in a temperature range from 110 to $140^{\circ} \mathrm{C}$. The temperature change is imposed by a linear ramp of 5 ${ }^{\circ} \mathrm{C} / \mathrm{min}$. As the actual reaction temperature differs from the linear shape due to the high heat production, the measured experimental temperature is used for the model calculation. 


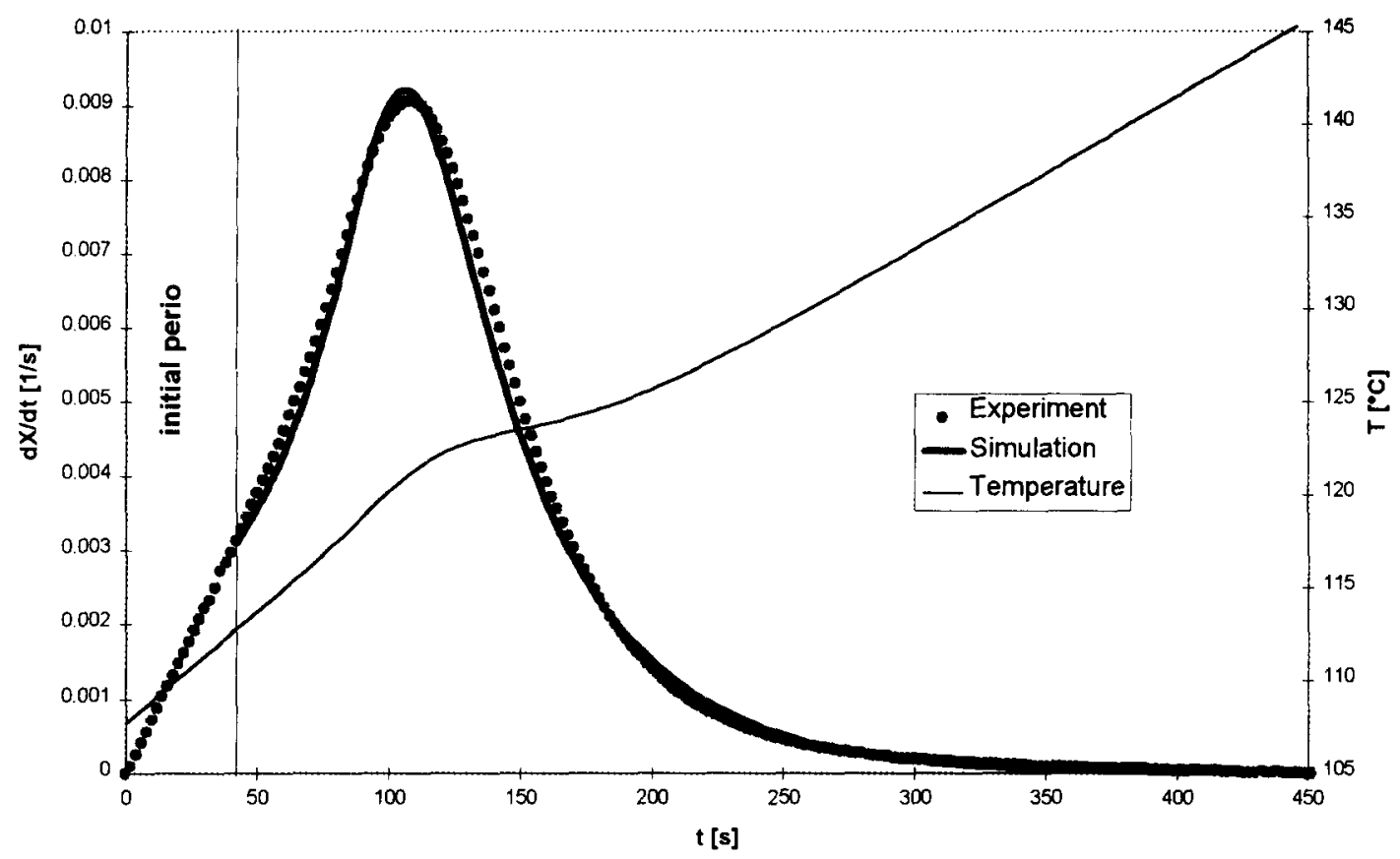

Figure 4 Simulation of a DSC curve. The system is BA:HEMA (50:50\% mass), 0.38 mol \% BPO. The temperature varies form 105 to $145^{\circ} \mathrm{C}$ at $5 \% \mathrm{~min}$. The continuous bold line is the calculated curve, the dots are the experimental points.

\section{POLYMERISATION IN A CONTINUOUSLY OPERATING BUSS-KNEADER}

The co-polymerisation of butylacrylate and 2-hydroxyethylmethacrylate is carried out in a Buss-Kneader. The monomers are pre-mixed and fed with a gear pump. To avoid prepolymerisation in the storage tanks, the peroxide is dosed separately with a mechanical syringe. Monomers and initiator are mixed in a static mixer just before they enter the kneader.

The screw and the barrel of the kneader are heated with oil to a constant temperature of $125^{\circ} \mathrm{C}$. As for the kinetic measurements a mixture of 50/50\%(mass) of BA and HEMA without any solvent are used.

The axial temperature profile in the kneader is determined with six $\mathrm{Fe} / \mathrm{Co}$-thermocouples. The screwspeed is varied between 60 and $285 \mathrm{rpm}$ and the throughput is changed from 1 to $8 \mathrm{l} / \mathrm{h}$.

To analyse the final conversion $0.3 \mathrm{~g}$ of a sample is dissolved in $10 \mathrm{ml}$ tetrahydrofurane (THF). The solution is analysed on the amount of BA and HEMA by gas chromatography (GC) to determine the monomer conversions. The analyses were carried out on a Hewlett Packard GC with a column of $25 \mathrm{~m}$, Fused Silica CP Sil 5 CB (i.d. $0.53 \mathrm{~mm}, \mathrm{~d}_{\mathrm{f}}=1.0 \mu \mathrm{m}$ ) and helium as carrier gas.

\section{RESULTS}

The conversion of HEMA is always higher than $95 \%$, whereas BA is converted typically to $70-90 \%$, depending on reaction conditions.

Based on the kinetic model presented and the kinetic parameters obtained from DSC experiments, axial temperature and concentration profile were calculated and compared with the experimental results in Fig. 5 . The reactor behaviour can be best described by a dispersion model. Under stationary conditions the following equations result from the mass and heat balances: 


$$
\begin{aligned}
& -\frac{d X_{M}}{d Z}+\frac{1}{B o} \frac{d^{2} X_{M}}{d Z^{2}}+\frac{\tau}{c_{M, 0}} R_{M}=0 \\
& -\frac{d X_{I}}{d Z}+\frac{1}{B o} \frac{d^{2} X_{I}}{d Z^{2}}+\frac{\tau}{c_{I, 0}} R_{I}=0 \\
& -\frac{d X_{Y}}{d Z}+\frac{1}{B o} \frac{d^{2} X_{Y}}{d Z^{2}}+\frac{\tau}{c_{Y, 0}} R_{Y}=0 \\
& -\frac{d X_{\Lambda}}{d Z}+\frac{1}{B o} \frac{d^{2} X_{\Lambda}}{d Z^{2}}-\frac{\tau}{c_{\Lambda, 0}} R_{\Lambda}=0 \\
& -\frac{d T}{d Z}+\frac{1}{P e_{h}} \frac{d^{2} T}{d Z^{2}}+\Delta T_{a d} \cdot \tau \cdot\left(\frac{-R_{M}}{c_{M_{0}}}\right)+S t_{h}\left(T_{o i l}-T\right)=0
\end{aligned}
$$

where.

$$
Z=\frac{z}{L} \quad B o=\frac{u \cdot L}{D_{a x}} \quad P e_{h}=\frac{u \cdot L}{a}
$$

with: $\quad a=\frac{\lambda}{\rho \cdot c_{p}}$

$$
\Delta T_{a d}=\frac{-\Delta H \cdot c_{M_{0}}}{\rho \cdot c_{p}} \quad \text { and } \quad S t_{h}=\frac{U \cdot\left(\frac{A}{V}\right) \cdot \tau}{\rho \cdot c_{p}}
$$

The differential equations are solved simultaneously to calculate the conversion or concentration profiles of the reaction partners and the temperature profile. As can be seen in Fig. 5, no pronouced hot-spot is observed, although the adiabatic temperature rise is approximately $300{ }^{\circ} \mathrm{K}$. This indicates an important backmixing in the kneader. The reason may be that, within the first quarter of the kneader, the conversion is low, resulting in a nonviscous fluid. Compared to experiments with molten polymers (Elemans, 1989), the Bodenstein number should therefore be considerably lower. We assume a value of $\mathrm{BO}=10$ under the actual reaction conditions. The temperature profile was found to be very sensitive to the Péclet number $\left(\mathrm{Pe}_{\mathrm{h}}\right)$ characterising the heat dispersion. As the reactor inlet is cooled with water, the wall temperature increases from $15^{\circ} \mathrm{C}$ to the constant value of 125 ${ }^{\circ} \mathrm{C}$. This is taken into account for the numerical simulations by assuming a cold zone of $3.5 \mathrm{~cm}$ at the inlet. The sensitivity towards the Péclet-number can be seen in Fig. 5, where three different profiles are compared to the measured one. The difference between measured and calculated profiles can be explained by the simplified reactor model, assuming a constant dispersion over the lenght of the kneader, which takes not into account the dramatic axial viscosity change. 


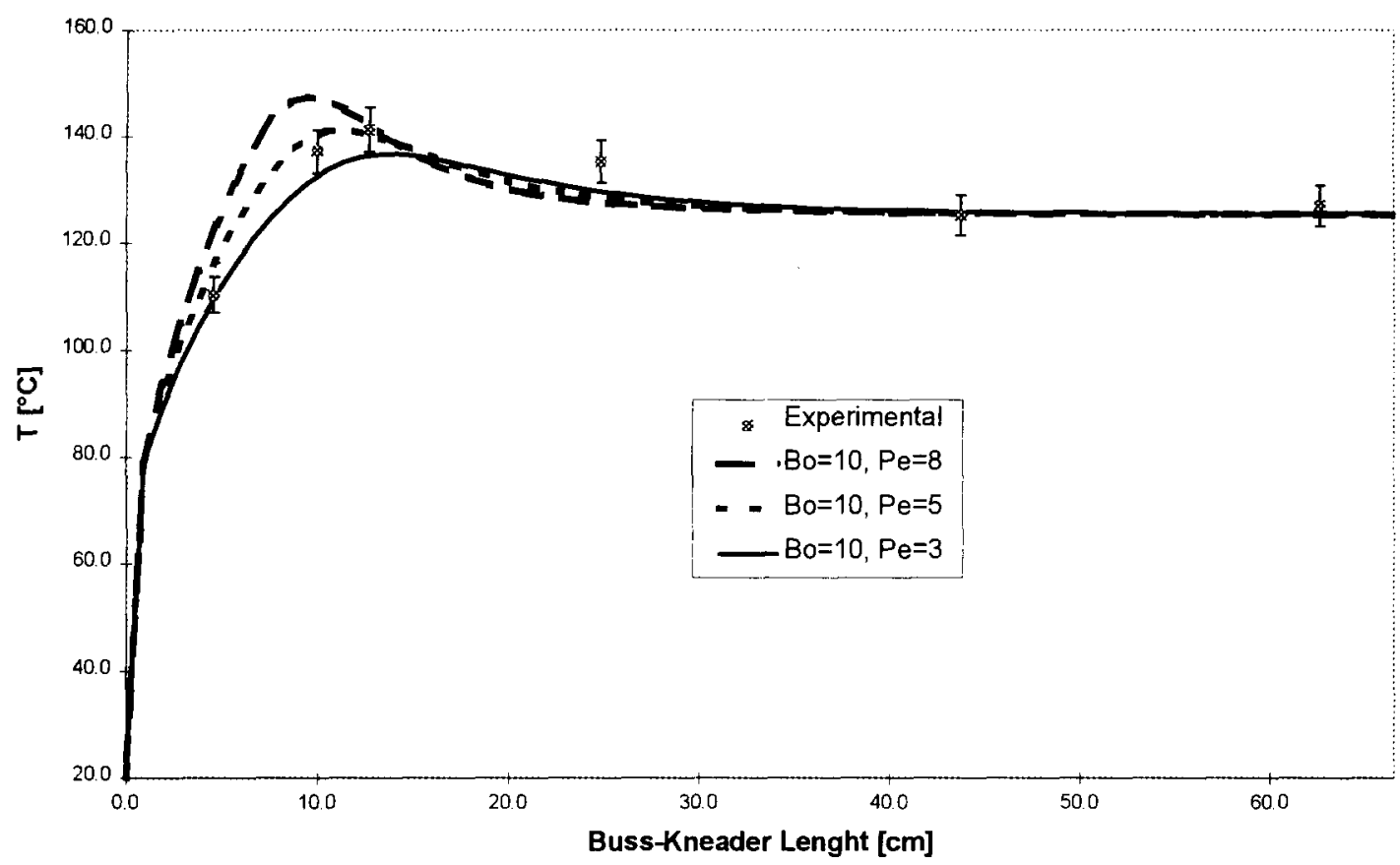

Figure 5 Example of measured and calculated temperature profile. Screw and barrel temperature are $125^{\circ} \mathrm{C}$, and the residence time is $10 \mathrm{~min}$. $U$ is taken as $650 \mathrm{~W} \mathrm{~m}^{2} \mathrm{~K}^{-1}$. The experimental temperature is an average over 10 different experiments, where the screwspeed is varied from 67 to $285 \mathrm{RPM}$. The error bar on the experimental points represent a standard deviation of about $3 \%$. The reaction mixture is HEMA/BA (50/50\% mass), Luperox $26 \mathrm{R} 0.5$ mole\% as initiator.

\section{CONCLUSIONS.}

DSC is a helpful tool to investigate overall polymerisation reaction kinetics, even for complex copolymerisation processes. There exists an excellent agreement between measured and calculated batchwise experiments.

The continuously operating Buss-Kneader shows its ability to polymerize co-polymers within reasonable residence times and acceptable temperature profiles without using any solvents.

Temperature profiles over the length of the Buss kneader were calculated by using a dispersion model. The Bodenstein number as well as the Péclet number, used in the model, were roughly estimated. Further research will be focused on measuring these estimated values

\section{ACKNOWLEDGEMENT}

This study is supported by DSM-Research (Geleen, The Netherlands), Buss AG (Basel, Switzerland) and KWF (Bern, Switzerland). 


\section{NOMENCLATURE}

\begin{tabular}{|c|c|}
\hline BPO & Benzoyl peroxide \\
\hline BA & Butyl Acrylate \\
\hline HEMA & 2-Hydroxy Ethyl Methacrylate \\
\hline THF & Tetra hydro furane \\
\hline$\rho$ & density \\
\hline$\delta$ & flight clearance \\
\hline$\lambda$ & heat conductivity \\
\hline$\Lambda_{0}$ & total radical concentration \\
\hline$\Delta \mathrm{h}$ & reaction enthalpy measured by DSC \\
\hline$\Delta \mathrm{H}$ & polymerisation heat \\
\hline$\tau$ & residence time \\
\hline A & heat exchanging area \\
\hline$A_{i}$ & pre-exponential factor \\
\hline$a\left(\approx \lambda / \rho C_{p}\right)$ & thermal diffusivity \\
\hline Bo & bodenstein number \\
\hline $\mathrm{C}_{\mathrm{M}, 0}, \mathrm{C}_{\mathrm{I}, 0}, \mathrm{C}_{\mathrm{Y}, 0}$ & initial concentration of monomer, initiator, inhibitor \\
\hline $\mathrm{C}_{\mathrm{M}}, \mathrm{C}_{\mathrm{l}}, \mathrm{C}_{\mathrm{Y}}$ & concentration of monomer, initiator, inhibitor \\
\hline$c_{p}$ & specific heat \\
\hline D & diameter \\
\hline $\mathrm{E}$ & energy \\
\hline $\mathrm{E}_{1}$ & activation energy \\
\hline f & degree of fill \\
\hline$f_{1}$ & initiator efficiency factor \\
\hline$h$ & mean heat transfer coefficient \\
\hline $\mathbf{k}_{\mathrm{d}}, \mathbf{k}_{\mathrm{p}}$ & initiator dissociation and monomer propagation kinetics constants \\
\hline $\mathrm{k}_{\mathrm{t}}, \mathrm{k}_{\mathrm{y}}$ & termination and inhibition kinetics constants \\
\hline $\mathrm{L}$ & Buss kneader lenght \\
\hline $\mathrm{N}$ & screwspeed \\
\hline $\mathrm{Pe}_{\mathrm{h}}$ & Péclet number \\
\hline $\mathrm{q}_{\mathrm{in}}$ & heat flow measured by DSC \\
\hline$Q_{v}$ & volumetric throughput \\
\hline $\mathrm{R}$ & perfect gas constant \\
\hline $\mathrm{R}_{\mathrm{I}}, \mathrm{R}_{\mathrm{M}}$ & initiation and propagation rates \\
\hline $\mathbf{R}_{\mathbf{Y}}, \mathbf{R}_{\Lambda 0}$ & inhibition and radical formation rates \\
\hline$i$ & average residence time \\
\hline$t_{b t}$ & break through time \\
\hline $\mathrm{T}, \mathrm{T}_{1}, \mathrm{~T}_{2}$ & material temperature \\
\hline $\mathrm{T}_{\mathrm{o} l}$ & temperature of the heating oil \\
\hline $\mathrm{U}$ & overall heat transfer coefficient \\
\hline $\mathrm{V}$ & reactor volume \\
\hline $\mathrm{X}$ & global monomer conversion \\
\hline$X_{M}, X_{I}, X_{Y}$ & conversion of monomer, initiator, inhibitor \\
\hline$Y_{A n}$ & Radical yield \\
\hline
\end{tabular}

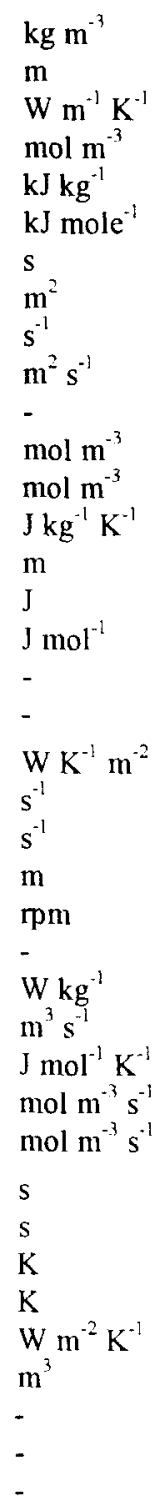




\section{REFERENCES}

Aeppli, H.D., 1989, Verfahrenschritte im Ko-Kneter, Plastverarbeiter 40, 108.

Elemans, P, 1989, Modelling of the processing of incompatible polymer Blends, Ph. D. Thesis, Technical University Eindhoven.

Fleury P.-A., 1993, Polymérisation du méthacrylate de méthyle à haute température, Ph. D. Thesis, EPFLausanne

Franz, P., 1988, Herstellung von Silikonen, in Kunststofftechnik, Polymerreaktionen und reaktives Aufbereiten in kontinuierlichen Maschinen, VDI Verlag Düsseldorf, pp 210-224

Ganzeveld, K.J. and Janssen, L.P.B.M., 1993,Twin Screw Extruders as Polymerization Reactors for a Free Radical Homo Polymerization, The Can.J. of Chem.Eng. 71, 411.

Jepson, C.H., 1953, Future Extrusion Studies, Ind.Eng.Chem. 45, 992.

Jongbloed, H.A., Mulder, R.K.S. and Janssen, L.P.B.M., 1995, The Copolymerization of Methacrylates in a Counter-Rotating Twin-Screw Extruder, Polym.Eng.Sci. 35, 587.

Louie, M.B., Carat, G.M., Soong, D.S., 1985, Modeling the free radical solution and bulk polymerisation of methyl-methacrylate, J.Appl. Polym Sci. 30, 3985

Maeder S., Renken A., 1995, Experimental determination of reactivity ratio- radical bulk polymerisation of acrylic monomers-DECHEMA Monographs, 131, 433

Steiner E., Rey T., McCroskey P., 1990, SIMUSOLV-Reference Guide-Volume 2

Franz P., 1984, Der BUSS-Ko-Kneter in der Extrusiontechnologie, Zucker-und Süsswaren Wirtchaft, 10 